\title{
Analisis Senyawa $\beta$-Karoten pada Buah Pepaya (Carica papaya L.) Asal Kabupaten Konawe Selatan, Provinsi Sulawesi Tenggara
}

\section{Analysis of $\beta$-Carotene compounds in Papaya (Carica papaya L.) Fruit from Konawe Selatan District, Southeast Sulawesi Province}

\author{
Irman Idrus ${ }^{1,2, *(i)}$, Sabda Wahab ${ }^{2}$, A. Fitrah Nugraha ${ }^{3}$, dan Syaiful Bachri ${ }^{4}$
}

\begin{abstract}
${ }^{1}$ Program Studi Farmasi, Universitas Kader Bangsa, Palembang 30452-Sumatra Selatan, Indonesia
${ }^{2}$ Program Studi Farmasi, STIKES Pelita Ibu, Kendari 93231-Sulawesi Tenggara, Indonesia

${ }^{3}$ Magister Manajemen Kesehatan, STIE AMKOP Makassar 90222-Sulawesi Selatan, Indonesia ${ }^{4}$ Laboratorium Analisis, BPOM Kendari, Kendari 93231-Sulawesi Tenggara, Indonesia.
\end{abstract}

*Corresponding author: irmanidrus80@gmail.com

Received: May 28, 2021

Received in revised: August 5, 2021

Accepted: August 6, 2021

Available online: August 31, 2021

\begin{abstract}
South Konawe District at Southeast Sulawesi Province is a producer of agriculture such as Papaya fruit ranging from 1168 quintals each year. Papaya fruit contains $\beta$-carotene which plays an important role in the formation of vitamin $A$ in the body. This research was conducted to determine the $\beta$-carotene content of papay a fruit by using variables planting method, fruitage, and fruit condition. The mashed fruit was extracted using $n$-hexane: acetone: ethanol (2: 1: 1) $\mathrm{v} / \mathrm{v}$, then separated from polar and non-polar solutions. Qualitative analysis was carried out using the Carr-Price method and quantitative analysis or determination of $\beta$-carotene levels using the UV-Visible spectrophotometric method $\lambda=$ $452.0 \mathrm{~nm}$. The qualitative test results showed that the papaya fruit in the papaya fruit obtained by cultivation and growing wild with each variable half-ripe, ripe, and not fresh papaya identified the presence of $\beta$-carotene. The results of quantitative analysis of $\beta$ carotene levels in cultivated papaya fruit were $1.76 \mu \mathrm{L}$, half-ripe $1.32 \mu \mathrm{L}$, and cultivated young papaya $1.22 \mu \mathrm{L}$. In wild ripe papaya $1.75 \mu \mathrm{L}$, wild half-ripe papaya $1.3 \mu \mathrm{L}$ and wild young papaya $1.21 \mu \mathrm{L}$. There is an effect of each test parameter starting from the parameters of planting method, fruitage, and fruit condition on $\beta$-carotene content in papaya fruit.
\end{abstract}

Keywords: $\beta$-carotene, Papaya (Carica papaya L), UV-Vis Spectrophotometry

\begin{abstract}
Abstrak (Indonesian)
Kabupaten Konawe Selatan Provinsi Sulawesi Tenggara merupakan penghasil pertanian seperti buah Pepaya berkisar 1168 kwintal setiap tahun. Buah pepaya mengandung $\beta$ karoten yang berperan penting bagi pembentukan vitamin A dalam tubuh. Penelitian ini dilakukan untuk mengetahui kandungan $\beta$-karoten buah Pepaya dengan variabel cara tanam, umur buah, dan kondisi buah. Buah yang telah dihaluskan diekstraksi menggunakan n-heksan : a seton : etanol $(2: 1: 1) \mathrm{v} / \mathrm{v}$, kemudian dipisahkan larutan polar dan non -polar. Dilakukan analisis kualitatif dengan metode Carr-Price dan analisis kuantitatif atau penetapan ka dar $\beta$-ka roten dengan metode spektrofotometri UV-Visibel $\lambda=452,0 \mathrm{~nm}$. Ha sil penelitian; Hasil uji kualitatif menunjukan dalam buah pepaya pada buah Pepaya yang diperoleh secara budida ya dan tumbuh liar dengan masing-ma sing variabel Pepaya setengah matang, matang dan tidak segar teridentifikasi a danya $\beta$-karoten. Hasil analisis kuantitatif kadar $\beta$-ka roten pada buah Pepaya budidaya matang $1,76 \mu \mathrm{L}$, setengah matang $1,32 \mu \mathrm{L}$, dan pepaya muda budidaya $1,22 \mu \mathrm{L}$. Pada buah pepaya matang liar $1,75 \mu \mathrm{L}$, buah pepaya setengah matang liar 1,3 $\mu \mathrm{L}$ dan buah pepaya muda liar 1,21 $\mu$ l. Ada penga ruh dari tiap-tiap paramaeter uji mulai dari parameter cara tanam, umur buah dan kondisi buah terhadap kandungan $\beta$-karoten Pada buah Pepaya.
\end{abstract}

Kata Kunci: $\beta$-karoten, Carica papaya. L, Spektrofotometri UV-Vis. 


\section{PENDAHULUAN}

Indonesia sebagai negara kepulauan memiliki hampir 17.508 pulau dengan garis pantai $81.000 \mathrm{~km}^{2}$, perairan teritorial 0,3 juta $\mathrm{km}^{2}$ dan perairan nusantara 2,8 juta $\mathrm{km}^{2}$ (Rondonuwu and Moningkey 2018). Wilayah pesisir dan laut di Indonesia memiliki kekayaan dan keanekaragaman hayati (biodiversity) terbesar di dunia, yang tercermin dari keberadaan ekosistem pesisir seperti hutan mangrove, terumbu karang, rumput laut dan berbagai jenis ikan, baik ikan hias maupun ikan konsumsi (Dahuri 2001). Bebagai kegiatan pemberdayaan masyarakat pesisir sebagai salah satu upaya untuk meningkatkan partisipasi masyarakat pesisir Kabupaten Konawe Selatan Provinsi Sulawesi Tenggara (Elmi Sumiyarsono 2010).

Kabupaten Konawe Selatan merupakan bagian dari provinsi Sulawesi Tenggara (Umar 2016). Secara geografis, Kabupaten Konawe Selatan terletak di bagian selatan garis khatulistiwa, membentang dari utara ke selatan antara $3^{\circ} .58 .56$ 'dan $4^{\circ} .31 .52^{\prime}$ Lintang Selatan dan membentang dari barat ke timur antara 121.58 'dan 123.16' Bujur Timur (Ruslan 2017).

Luas wilayah daratan Kabupaten Konawe Selatan $451.421 \mathrm{Ha}$ atau $11,83 \%$ dari luas wilayah daratan Sulawesi Tenggara. Sedangkan luas wilayah perairan (laut) diperkirakan seluas $9.368 \mathrm{Km}^{2}$ (Muniaha and Nur 2017). Selain jazirah tenggara Pulau Sulawesi, terdapat juga pulau kecil yaitu Pulau Cempedak yang merupakan bagian dari Kecamatan Laonti (Hasjad 2020).

Berdasarkan hasil sensus tahun 2005, penduduk usia 10 tahun ke atas sekitar $75,09 \%$ atau 173.742 orang, terdiri dari angkatan kerja yang termasuk bekerja $59,85 \%$ dan mencari pekerjaan $40,15 \%$ atau 69.759 orang (Putrawan et al. 2016). Jumlah pencari kerja yang terdaftar di Dinas Tenaga Kerja dan Imigrasi adalah 2.764 orang pada tahun 2005. Dari 2.764 pencari kerja, terdapat 1.326 orang atau sekitar $47,97 \%$, berpendidikan menengah, dan 954 orang, atau sekitar 34,52\%, memiliki gelar sarjana atau lebih, dan 467 orang, atau sekitar $16,90 \%$, memiliki pendidikan DIII/gelar sarjana dan jenjang pendidikan lainnya semuanya kurang dari 10 persen (Putrawan et al. 2016).

Produksi beras tercatat 66.610 ton atau naik $19,26 \%$, ubi kayu 12.437 ton sebesar 5,41\%, kacang hijau 160 ton naik $21,21 \%$, kedelai 1.669 ton naik 21,03\%, dan ubi jalar 2.022 ton (Fausayana and Miniarti 2019), atau naik 55,18\%, jagung 3.919 ton atau $4,26 \%$, dan kacang tanah 312 ton naik $6,49 \%$. Hasil panen kacang panjang 5.131 kuintal, terong 2.748 kuintal, tomat 2.103 kuintal, lobak 10.577 kuintal, cabai rawit 3.766 kuintal, ketimun 8.076 kuintal, sawi 9.135 kuintal, dan bawang hijau 838 kuintal. Produksi tanaman pertanian terbesar adalah kakao 69.987 ton dan kacang mete 5.161 ton. Lada dan kelapa masing-masing 1022 ton dan 2.590 ton. Jenis tanaman lain menghasilkan kurang dari 1000 ton. Produksi buah tahun 2005 tercatat sebagai berikut: mangga sebanyak $6158 \mathrm{kwintal}$, langsat $3.654 \mathrm{kwintal}$, pisang $25.746 \mathrm{kwintal}$, nanas $1141 \mathrm{kwintal}$, rambutan 2.648 kwintal, dan Pepaya 1168 kwintal (Fausayana and Miniarti 2019).

Tanaman pepaya sangat mudah tumbuh sehingga banyak dijumpai berbagai belahan dunia misalnya di Amerika Tengah dan Selatan serta Afrika Utara, India, Indonesia, Malaysia, Thailand, dan Sri Lanka (Wakatobi 2019). Pepaya dapat tumbuh optimal pada ketinggian 200-500 meter dpl dengan suhu antara 25$30^{\circ} \mathrm{C}$ dan kelembaban udara sekitar $40 \%$ dan tumbuh subur di daerah hujan 1000-2000 mm/tahun pada ketinggian lebih dari $500 \mathrm{mdpl}$ (Elizabeth 2015). Pepaya menjadi lambat dan rasa buah kurang manis tumbuh di dataran tinggi, selain rentan terserang penyakit karena kondisi kelembapan yang relatif tinggi (Dewi 2021).

Buah pepayamengandung banyak vitamin terutama vitamin $A$, vitamin $B$ 9, vitamin $C$, dan vitamin $\mathrm{E}$, mineral seperti fosfor, magnesium, zat besi dan kalsium. Kandungan vitamin C : 70,2 mg/100 gram, betakaroten: 20,722 mikrogram/100 gram (Sari and Firdaus 2019). Vitamin A sangat penting dalam kehidupan manusia karena dapat meningkatkan sistem kekebalan tubuh (Amalia et al. 2020). Mengkonsumsi buah pepaya dapat meningkatkan daya tahan tubuh dan mencegah berbagai penyakit seperti pilek, batuk, infeksi dan flu. Selain itu, juga terkandung enzim papain dan kemopapen yang dapat mengurangi peradangan sehingga membantu tubuh menyembuhkan luka bakar dan luka lainnya (Budi 2016). Beberapa penyakit memburuk saat tubuh meradang (Budi 2016).

Buah Pepaya berperan dalam mencegah kanker usus besar. Hal ini tidak lepas dari kandungan seratnya yangbesar. Serat inijuga bermanfaat bagi mereka yang kesulitan buang air besar (Nurjanah and Ihsan 2013). Vitamin A yang terdapat pada pepaya sangat bermanfaat bagi penderita paru-paru lemah, serta dapat mengurangi kemungkinan berkembangnya penyakit yang muncul seperti bronkitis dan kanker (S Dalimartha 2011).

Vitamin A (beta karoten) dapat di analisis menggunakan alat Spektrofotometer UV-Visible, karena alat ini sangat umum digunakan di laboraturium kimia untuk analisa kimia kuantitatif, namun dapat juga digunakan untuk analisa kimia semi kualitatif (Arnovia 2012). Spektrofotometri serapan merupakan 
pengukuran suatu interaksi antara radiasi elektromagnetik dan molekul atau atom dari suatu zat kimia (Alfian 2018). Teknik yang sering digunakan dalam analisis farmasi meliputi spektroskopi serapan ultraviolet, cahaya tampak, inflamerah dan serapan atom (Lokasari and Putri 2019). Pengukuran spektrofotometri di dalam daerah cahaya tampak mulamula disebut kolorimetri, tetapi istilah kolorimetri lebih tepat digunakan untuk persepsi tentang wama (Li'ibaadatillaah 2017).

Hasil penelitian sebelumnya yang mengemukakan bahwa budidaya mengkudu terbukti berpengaruh pada tingginya kandungan betakaroten pada daun mengkudu, kandungan betakaroten daun mengkudu budidaya ternyata lebih tinggi dibanding mengkudu yang tumbuh liar. Faktor pemupukan, kad ar air, sifat tanah dan kandungan organik tanah sangat pengaruh terhadap kandungan betakaroten. Daun Mengkudu budidaya mengandung betakaroten $8,1 \mathrm{mcg} / 100 \mathrm{~g}$, dan 7,2 mcg/100 g untuk dau muda, sedangkan daun Mengkudu yang tumbuh liar mengandung betakaroten $3,7 \mu \mathrm{g} / 100 \mathrm{~g}$ dan $3,3 \mu \mathrm{g} / 100 \mathrm{~g}$ daun mengkudu muda. Dari kondisi daun yang mempengaruhi kandungan betakaroten pada daun (Rohman et al. 2016). Metode ekstraksi mempengaruhi kandungan betakaroten pada daun mengkudu, karena betakaroten tidak tahan panas, sehingga metode ekstraksi panas tidak dapat digunakan untuk menentukan betakaroten karena dapat merusak kandungan dalam sampel (Magfirah 2018). Sedangkan menurut penelitian lainnya mengemukakan bahwa buah pepaya mengandung vitamin $\mathrm{C}$ dan betakaroten yang bermanfaat sebagai antioksidan. Dalam buah pepaya mengandung vitamin $\mathrm{C} 70,2 \mathrm{mg} / 100$ gram berat pepaya dan kandungan betakaroten 20,722 mikrogram/100 gram.

Berdasarkan uraian diatas, penulis tertarik untuk mengetahui cara tanam, umur buah, kondisi buah dan penetapan kadar vitamin A ( $\beta$-karoten) dari ekstrak buah pepaya (Carica papaya L.) dengan metode spektofotometri UV-Visibel, dengan tujuan untuk mengetahui pengaruh cara tanam, pengaruh umur buah, dan pengaruh kondisi buah terhadap kandungan vitamin A ( $\beta$-karoten).

\section{METODOLOGI}

\section{Penyiapan Sampel Penelitian}

Sampel Pepaya muda, mengkal (setengah matang) dan matang sebanyak 500 gram, dibersihkan dengan cara dicuci dengan air mengalir untuk menghilangkan kotoran dan senyawa anorganik lainnya, kemudia di potong kecil-kecil kemudian dihaluskan dengan blender. Ditimbang 50 gram, dimasukkan ke dalam
Erlenmeyer bertutup yang dilapisi dengan kertas aluminium foil pada bagian luar agar terlindungi dari cahaya. Ditambahkan $50 \mathrm{ml}$ larutan (heksana, aseton, etanol = 2:1:1) $\mathrm{v} / \mathrm{v}$ dikocok selama 30 menit dengan magnetic stirer, disaring dengan corong Buchner, selanjutnya bagian non polar diambil untuk digunakan sebagai pelarut sampel pada tahap uji kualitatif dan kuantitatif (Kamelia 2018).

\section{Analisis kualitatif $\beta$-karoten}

\section{Pembuatan Larutan Pereaksi 25\%}

Larutan antimon triklorida dibuat dengan melarutkan 2,5 gram antimon triklorida dalam kloroform sampai $10 \mathrm{ml}$ dimasukan dalam labu ukur kemudian kocok hingga homogen. Uji kualitatif menggunakan metode Carr-Price dengan mengambil larutan antimon triklorida $25 \%$ dalam kloroform $10 \mathrm{ml}$. Ekstrak cair yang diperoleh dipipet $2 \mathrm{ml}$, tambahkan larutan antimon triklorida, jika terbentuk perubahan warna biru sebagai hasil dari reaksi antara pro-vitamin A dengan antimon triklorida dalam kloroform pada larutan sampel maka positif mengandung $\beta$-karoten.

\section{Analsisi kuantitatif $\beta$-karoten}

Pembuatan larutan baku $\beta$-karoten standar $50 \mathrm{mg}$ dimasukan dalam labu ukur $50 \mathrm{ml}$ dilarutkan dengan etanol absolut p.a.hingga diperolehkonsentrasi larutan induk sebesar $1 \mathrm{mg} / \mathrm{mL}$.

\section{Uji Kuantitatif $\beta$-karoten}

1) Penetapan Operating Time Diambil 0,25 mL larutan induk baku 3 -karoten masukan dalam labu takaran $50 \mathrm{~mL}$. Larutan baku B-karoten $50 \mu \mathrm{g} / \mathrm{mL}$ dibaca serapannya pada panjang gelombang $452 \mathrm{~nm}$ sampai diperoleh waktu serapan yang stabil.

2) Penetapan Panjang Gelombang Serapan Maksimum, larutan baku ß-karoten $50 \mu \mathrm{g} / \mathrm{mL}$ dibaca serapannya pada panjang gelombang 350$550 \mathrm{~nm}$ diukur waktu puncak serapan maksimum yang diperoleh.

3) Penentuan Kurva Baku dibuat seri larutan $\beta$ karoten $50 \mu \mathrm{g} / \mathrm{mL}$ dalam labu takaran $50 \mathrm{~mL}$ yaitu 2,0 $\mu \mathrm{g} / \mathrm{mL}, 4,0 \mu \mathrm{g} / \mathrm{mL}, 6,0 \mu \mathrm{g} / \mathrm{mL}, 8,0 \mu \mathrm{g} / \mathrm{mL}$, dibaca pada operating time dan panjang gelombang serapan maksimum yang diperoleh.

4) Pengukuran Serapan

Residu dari buah pepaya muda, mengkal (setengah matang) dan matang dimasukkan ke dalam labu takar $10 \mathrm{ml}$ kemudian ditambah pelarut organik n-heksan p.a sampai tanda batas dan dibaca serapannya. 
Data kuantitatif seperti kandungan $\beta$-karoten Pepaya mentah, pepaya setengah matang (mengkal) dan buah matang diuji secara statistik dengan uji parameter ANOVA menggunakan SPSS. Anda dapat menentukan di mana hipotesis diterima atau ditolak. Jika ada perbedaan pada uji ANOVA, lanjutkan ke uji post hoc untuk melihat apa perbedaannya.

\section{HASIL DAN PEMBAHASAN}

Pada penelitian ini menggunakan filtrat utuh buah pepaya (Carica papaya L.) yang diperoleh dari budidaya tanaman di kebun masyarakat Laonti Kabupaten Konawe Selatanyang telah diblender. Buah Pepaya yang diperoleh yaitu 500 gram buah budidaya dan 500 gram buah liar. Dipisahkan dengan parameter tanaman yaitu umur buah (muda, mengkal dan matang) dan kondisi buah (segar dan tidak segar) serta buah Pepaya segar, dipetik langsung dari pohonnya. Buah pepaya mudakemudian dipotong dan dicuci dengan air mengalir guna untuk menghilangkan kotoran. Kemudian dihaluskan menggunakan blender. Untuk buah pepaya setengah matang, matang, segar dan tidak segar dilakukan dengan proses yang sama.

Bahan yang didapat pada penelitian ini adalah $\beta$ karoten $30 \%$, serta pelarut etanol absolut p.a dan pereaksi antimon (III) khlorida dan kloroform. Metode yang digunakan pada penelitian ini adalahbuah Pepaya yang sudah diblender ditambahkan pelarut $(\mathrm{N}$-heksana, aseton, etanol) dengan perbandingan (2:1:1) kemudian didapatkanlah hasil larutan non-polar. Hasil larutan non-polar yang selanjutnya digunakan untuk uji kualitatif dan uji kuantitatif.

Tabel 1. Hasil Parameter Tanaman

\begin{tabular}{cccc}
\hline \multirow{2}{*}{ No } & & \multicolumn{3}{c}{ Parameter } \\
\cline { 2 - 4 } & Cara tanam & Umur buah & Kondisi buah \\
\hline 1 & Budidaya & Mudah & Segar (baru dipetik) \\
2 & Tumbuh liar & Mengkal & Buah yang sud ah lama (yang banyak di pasaran) \\
3 & Budidaya & Matang & Baru dipetik \\
\hline
\end{tabular}

Tabel 2. Hasil filtrat buah Pepaya (Carica papaya L.) berdasarkan cara tanam dan umur buah

\begin{tabular}{cccc}
\hline No. & Buah Pepaya & Filtrat (Budidaya) & Filtrat (Liar) \\
\hline 1. & Muda & 250 gram & 250 gram \\
2. & Mengkal (setengah matang) & 245 gram & 245 gram \\
3. & Matang & 265 gram & 265 gram \\
\hline
\end{tabular}

Tabel 3. Hasil filtrat buah Pepaya (Carica papaya L.) berdasarkan kondisi buah

\begin{tabular}{ccc}
\hline No. & Buah Pepaya & Filtrat \\
\hline 1. & Segar & 250 gram \\
2. & Tidak Segar & 265 gram \\
\hline
\end{tabular}

Tabel 4. Hasil filtrat buah Pepaya (Carica papaya L.) berdasarkan cara tanam dan umur buah

\begin{tabular}{cccc}
\hline No & Buah Pepaya & Larutan Non Polar (B) & Larutan Non-polar (L) \\
\hline 1. & Muda & $14 \mathrm{~mL}$ & $14 \mathrm{~mL}$ \\
2. & Mengkal (setengah matang) & $18 \mathrm{~mL}$ & $18 \mathrm{~mL}$ \\
3. & Matang & $20 \mathrm{~mL}$ & $20 \mathrm{~mL}$ \\
\hline
\end{tabular}

Tabel 5. Hasil filtrat buah Pepaya (Carica papaya L.) berdasarkan kondisi buah

\begin{tabular}{ccc}
\hline No & Buah Pepaya & Larutan Non-polar \\
\hline 1. & Segar & $10 \mathrm{~mL}$ \\
2. & Tidak Segar & $15 \mathrm{~mL}$ \\
\hline
\end{tabular}


Tabel 6. Hasil uji kualitatif metode Carr-Price berdasarkan cara tanam dan umur buah.

\begin{tabular}{lccc}
\hline \multirow{2}{*}{ No. } & \multirow{2}{*}{ Nama Tumbuhan } & \multicolumn{2}{c}{ Hasil Carr-Price } \\
\cline { 2 - 4 } & Buah pepaya muda & - & Filtrat (L) \\
\hline 1. & Buah pepaya setengah matang & + & - \\
2. & Buah pepaya matang & + & + \\
3. & & + & + \\
\hline
\end{tabular}

Tabel 7. Uji kualitatif dengan metode Carr-Price berdasarkan kondisi buah

\begin{tabular}{ccc}
\hline No & Nama Tumbuhan & Hasil Carr-Price \\
\hline 1. & Buah pepaya segar & - \\
2. & Buah pepaya tidak segar & + \\
\hline
\end{tabular}

Tabel 8. Serapan larutan $\beta$-karoten standar pada beberapa konsentrasi

\begin{tabular}{cc}
\hline $\mathbf{C}(\boldsymbol{\mu g} / \mathbf{m L})$ & Serapan $(\mathbf{A})$ \\
\hline 2,0 & 0,438 \\
4,0 & 0,866 \\
6,0 & 1,294 \\
8,0 & 1,777 \\
\hline
\end{tabular}

Tabel 9. Hasil penetapan kadar $\beta$-karoten dari filtrat buah pepaya (Carica papaya L.) berdasarkan cara tanam dan umur buah

\begin{tabular}{ccccccc}
\hline No. & $\begin{array}{c}\text { Sampel Buah } \\
\text { Pepaya }\end{array}$ & Cara Tanam & $\begin{array}{c}\text { Konsentrasi } \\
(\boldsymbol{\mu} \mathbf{l} / \mathbf{m L})\end{array}$ & Serapan $(\mathbf{A})$ & Kadar $(\boldsymbol{\mu L})$ & $\mathbf{( \% )}$ \\
\hline \multirow{2}{*}{ 1. } & \multirow{2}{*}{ Muda } & Budidaya & 200 & 0,2539 & 1,22 & 0,61 \\
& & Liar & 200 & 0,2537 & 1,21 & 0,60 \\
\multirow{2}{*}{ 2. } & \multirow{2}{*}{ Setengah matang } & Budidaya & 200 & 0,2764 & 1,32 & 0,66 \\
\multirow{2}{*}{ 3. } & Matang & Liar & 200 & 0,2716 & 1,30 & 0,65 \\
& & Budidaya & 200 & 0,3749 & 1,76 & 0,88 \\
& & Liar & 200 & 0,3737 & 1,75 & 0,87 \\
\hline
\end{tabular}

Tabel 10. Hasil penetapan kadar $\beta$-karoten dari filtrat buah pepaya (Carica papaya L.) berdasarkan kondisi buah

\begin{tabular}{ccclcc}
\hline No. & Sampel Buah Pepaya & Konsentrasi & Serapan $(\mathbf{A})$ & $\operatorname{Kadar}(\boldsymbol{\mu L})$ & $\mathbf{( \% )}$ \\
\hline 1. & Segar & 200 & 0,2539 & 1,22 & 0,61 \\
2. & Lama (tidak segar) & 200 & 0,3744 & 1,76 & 0,88 \\
\hline
\end{tabular}

Hasil larutan non-polar buah pepaya selanjutnya dilakukan uji kualitatif dan uji kuantitatif. Uji kualitatif dilakukan dengan menggunakan metode Carr-Price dengan mencampurkan larutan pereaksi antimon (III) klorida 2,5 g dalam kloroform $10 \mathrm{~mL}$ dengan tujuan terjadi perubahan warna biru tidak tetap. Uji kualitatif pada ekstrak buah Pepaya (Carica papaya L.) dengan metode Carr-Price didapatkan hasil buah muda yang hidup secara budidaya dan liar tidak terbentuk warna biru (-). Hal ini menunjukan bahwa buah pepaya muda secara budidaya dan liar tidak terdeteksi mengandung $\beta$-karoten. Buah pepaya mengkal (setengah matang) dan matang yang hidup secara budidaya dan liar terbentuk warna biru (+). Hal ini menunjukan bahwa buah mengkal (setengah matang) dan buah matang yang hidup secara budidaya dan liar mengandung $\beta$ karoten. Buah Pepaya segar tidak terbentuk warna biru (-). Hal ini menunjukan bahwa buah segar tidak terdeteksi mengandung $\beta$-karoten. Sedangkan buah lama (tidak segar) terbentuk warna biru (+). Hal ini menunjukan bahwa buah lama (tidak segar) terdeteksi mengandung $\beta$-karoten.

Hasil uji kualitatif kemudian dilanjutkan dengan uji kuantitatif. Pada penelitian ini bertujuan untuk 
menghitung kadar $\beta$-karoten yang terkandung dalam larutan non-polar buah Pepaya (Carica papaya L.) dengan metode spektrofotometri UV-visibel. Uji kuantitatif dilakukan dengan membuat larutan baku standar secara seri dengan konsentrasi $2,0 \mu \mathrm{g} / \mathrm{mL}, 4,0$ $\mu \mathrm{g} / \mathrm{mL}, 6,0 \mu \mathrm{g} / \mathrm{mL}$, dan $8 \mu \mathrm{g} / \mathrm{mL}$. Dalam larutan $\mathrm{n}$ heksan absolut p.a. kemudian dibaca kadar serapannya pada operating time pada panjang gelombang serapan $350-550 \mathrm{~nm}$. Panjang gelombang maksimum yang diperoleh adalah $450 \mathrm{~nm}$.

Hasil dari pengukuran serapan larutan $\beta$-karoten standar. Persamaan regresi linier yang diperoleh menyatakan hubungan antara konsentrasi larutan $\beta$ karoten standar dengan serapan yaitu $\mathrm{Y}=0,222 \mathrm{X}-$ 0,017 dengan $r=0,9991$, dimana $Y$ adalah serapan dan $\mathrm{X}$ adalah konsentrasi dalam $\mu \mathrm{g} / \mathrm{mL}$.

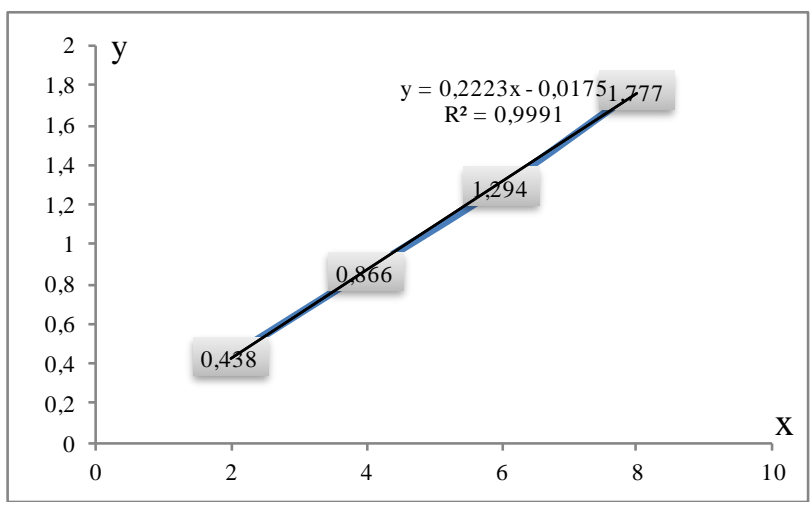

Gambar 1. Kurva hubungan antara konsentrasi larutan $\beta$-karoten standar dengan serapan.

Hasil dari uji kuantitatif kadar $\beta$-karoten buah pepaya didapatkan hasil untuk cara tanam dengan cara budidaya buah pepaya muda $1,22 \mu \mathrm{g}$, sedangkan dengan cara liar buah pepaya muda kadar $1,21 \mu \mathrm{g}$. Dapat dilihat bahwa kadar $\beta$-karoten buah pepaya muda budidaya lebih besar buah pepaya muda liar. Untuk cara tanam dengan cara budidaya buah pepaya setengah matang kadar $1,32 \mu \mathrm{g}$, sedangkan dengan cara liar buah pepaya setengah matang $1,30 \mu \mathrm{g}$. Dapat dilihat bahwa kadar $\beta$-karoten buah pepaya setengah matang budidaya lebih besar buah pepaya setengah matang liar.Untuk cara tanam dengan cara budidaya buah pepaya matang kadar $1,76 \mu \mathrm{g}$, sedangkan dengan cara liar buah pepaya matang kadar 1,75 $\mu$ g. Dapat dilihat bahwa kadar $\beta$ - karoten buah pepaya matang budidaya lebih besarbuah pepaya matang liar.

Umur buah pepaya muda budidaya kadar $1,22 \mu \mathrm{g}$, buah pepaya setengah matang budidaya kadar $1,32 \mu \mathrm{g}$, dan buah pepaya matang $1,76 \mu \mathrm{g}$. Dapat dilihat bahwa kadar $\beta$-karoten buah pepaya muda lebih kecil buah pepaya setengah matang lebih kecil buah pepaya matang. Untuk umur buah pepaya muda liar kadar 1,21 $\mu \mathrm{g}$, buah pepaya setengah matang $1,3 \mu \mathrm{g}$ dan buah pepaya matang $1,75 \mu \mathrm{g}$. Dapat dilihat bahwa kadar $\beta$ karoten buah pepaya muda lebih kecil buah pepaya setengah matang lebih kecil buah pepaya matang. Kondisi buah pepaya segar kadar $1,22 \mu \mathrm{g}$, sedangkan buah pepaya lama (tidak segar) $1,76 \mu \mathrm{g}$. Dapat dilihat bahwa kadar $\beta$-karoten buah pepaya segar lebih kecil buah pepaya lama (tidak segar).

Berdasarkan hasil penelitian, teori dan penelitian terkait peneliti menemukan bahwa kandungan kadar $\beta$ karoten pada buah pepaya matang lebih besar dari buah pepaya mengkal (setengah matang) dan buah pepaya muda, hal ini disebabkan karena warna dari buah pepaya matang berwarna kuning keorangean kemerahmerahan, buah pepaya mengkal (setengah matang) berwarna hijau kekuningan, dan buah pepaya muda dan segar berwarna hijau, sehingga kadar $\beta$ - karoten pada buah pepaya matang berwarna kuning keorangean kemerahan lebih tinggi. Buah pepaya yang diambil secara budidaya lebih besar kandungan kadar $\beta$-karotennya dari buah pepaya yang diambil secaraliar karena faktor yang berpengaruh pada cara tanam dapat berpengaruh pula pada kandungan $\beta$-karoten dari buah pepaya, faktor yang berpengaruh yaitu tekstur tanah, sumber air, cuaca, pemupukan, dan senyawa organik lainnya.

\section{KESIMPULAN}

Hasil penelitian tentang analisis senyawa $\beta$-karoten pada buah Pepaya (Carica papaya L.) asal Kabupaten Konawe Selatan, Provinsi Sulawesi Tenggara maka dapat di simpulan bahwa ada pengaruh dari setiap parameter uji terhadap kadar $\beta$-karoten pada Buah Pepaya mulai dari parameter cara tanam terhadap buah Pepaya setengah matang dan matang, juga ada pengaruh umur buah terhadap kadar $\beta$-karoten pada buah pepaya muda, setengah matang dan matang, serta terdapat pula pengaruh pengaruh kondisi buah terhadap kadar $\beta$-karoten pada buah Pepaya segar baru dipetik dan buah Pepaya lama yang ada dipasaran.

\section{DAFTAR PUSTAKA}

Alfian, M., 2018. Uji Aktivitas Antioksidan Dan Penetapan Kadar Fenolik Total Fraksi N-Heksan, Etil Asetat, Dan Air Ekstrak Etanol Daun Kersen (Muntingia calabura L.), Skripsi.

Amalia, L., Irwan, I., Hiola, F., 2020. Analisis Gejala Klinis dan Peningkatan Kekebalan Tubuh untuk Mencegah Penyakit Covid-19. Jambura J. Heal. Sci. Res. 2, 71-76.

Arnovia, W., 2012. Bentonit Pacitan Sebagai Adsorben Untuk Delororisasi Cpo (CrudePalm Oil) Skripsi 22-72. 
Budi, S., 2016. 378 Jus \& Ramuan Herbal: Tumpas Penyakit Ringan sampai Berat. PT. Kawan Pustaka.

Dahuri, R., 2001. Pengelolaan Ruang Wilayah Pesisir dan Lautan Seiring dengan Pelaksanaan Otonomi Daerah. Mimb. J. Sos. dan Pembang. 17, 139171.

Dewi, S., 2021. Jenis dan Populasi Lalat Buah (Tephritidae: Diptera) yang Menyerang Tanaman Cabai di Kota Padang, Disertasi, Universitas Andalas.

Elizabeth, P.S., 2015. Teknik BudidayaPepaya Calina.

Elmi Sumiyarsono, 2010. Partisipasi Masyarakat Daam Pembangunan dan Pengelolaan Prasarana Penyediaan Air Bersih di Desa Wawoosu dan Desa Mataiwoi Kecamatan Kolono Kabupaten Konawe Selatan Provinsi Sulawesi Tenggara.

Fausayana, I., Miniarti, Y., 2019. Perbedaan Pendapatan Peralihan Lahan Usahatani Padi Sawah Menjadi Usahatani Jeruk Nipis Di Desa Watabenua Kecamatan Landono Kabupaten Konawe Selatan. J. Ilm. Membangun Desa dan Pertan. 4, 117-121.

Hasjad, H., 2020. Pengembangan Pengelolaan Dana Desa Terhadap Kesejahtraan Masyarakat DesaDi Kabupaten Konawe Selatan Provinsi Sulawesi Tenggara. Ganaya J. Ilmu Sos. dan Hum. 3, 112125.

Kamelia, N.J., 2018. Aktivitas Antibakteri Fraksi Ekstrak Etanol Daun Putri Malu (Mimosa Pudica) Terhadap Methicillin Resistant Staphylococcus Aureus (Mrsa) Secara In Vitro. Disertasi, Universitas Brawijaya.

Li'ibaadatillaah, Z., 2017. Pengaruh konsentrasi ekstrak daun kenikir (Cosmos caudatus L.) terhadap karakteristik dan pelepasan senyawa aktif pada sistem nanoemulsi menggunakan fase minyak Virgin Coconut Oil (VCO). Disertasi, Universitas Islam Negeri MaulanaMalik Ibrahim

Lokasari, A.D.,Putri, O.K., 2019. Perbandingan Kadar Saponin Ekstrak Daun Waru (Hibiscustiliaceus L.) Segar dan Kering Menggunakanspektrofotometer Uv-Vis. Disertasi, Akademi Farmasi Putera Indonesia Malang

Magfirah, L., 2018. Uji Aktivitas Antibakteri FraksiFraksi Etanol dari Daun Mengkudu (Morinda citrifolia. L) Terhadap Bakteri Mycobacterium tuberculosis. Disertasi, Universitas Islam Negeri Alauddin Makassar.

Muniaha, H., Nur, A.I., 2017. Studi kelimpahan ikan karang berdasarkan kondisi terumbu karang di Desa Tanjung TiramKabupaten Konawe Selatan.
J. Manaj. Sumber Daya Perair. 2, 1, 9-19.

Nurjanah, N., Ihsan, N., 2013. Ancaman! Di Balik Segarnya Buah. Puspa Swara

Putrawan, A., Junaid, J., Ismail, C., 2016. Studi Kualitatif Pelaksanaan Jaminan Kesehatan Nasional Oleh Bpjs Kesehatan di Kecamatan Tinanggea Kabupaten Konawe Selatan. J. Ilm. Mhs. Kesehat. Masy., 1, 3, 1-9.

Rohman, A., Riyanto, S., Hidayati, N.K., 2016. Aktivitas Antioksidan, Kandungan FenolikTotal, dan Flavonoid Total Daun Mengkudu (Morinda citrifolia L). J. Agritech 27, 4, 147-151.

Rondonuwu, A.B., Moningkey, R.D., 2018. The Coral Fish in the Coastal Areas, Likupang Kampung Ambong Village, East Likupang District, North Minahasa Regency. J. Ilm. PLATAX 7, 1, 90-97.

Ruslan, R.A., 2017. Kesadaran Hukum Masyarakat Dalam Jual Beli Tanah Dengan Akta Ppat Di Kecamatan Tinanggea Kabupaten Konawe Selatan Sulawesi Tenggara. Disertasi, Fakultas Hukum, Unissula.

S Dalimartha, F.A., 2011. Khasiat Buah dan Sayur. Penebar Swadaya Grup.

Sari, S.A., Firdaus, M., 2019. Studi Pembuatan Sabun Cair dari Daging Buah Pepaya (Analisis Pengaruh Kadar Kalium Hidroksida terhadap Kualitas Sabun). Talent. Conf. Ser. Sci. Technol. 2, 60-65.

Umar, M.Z., 2016. Akulturasi Budaya pada Bentuk Atap Masjid di Kabupaten Konawe Selatan Sulawesi Tenggara. Etnoreflika J. Sos. dan Budaya 5, 1-14.

Wakatobi, D.I.K., 2019. Seminar nasional kelautan dan perikanan. Fak. Perikan. dan Ilmu Kelaut. Unpatti. Ambon 1, 26-36. 